\title{
MODALIZAÇÃO DOS SUJEITOS NO PROCESSO DE FORMAÇÃO DE LEITORES: UMA ANÁLISE SEMIÓTICA DO GOSTO ${ }^{1}$
}

\author{
MODALIZATION OF THE SUBJETCTS IN THE PROCESS OF \\ READERS' FORMATION: A SEMITIC ANALYSIS OF THE TASTE
}

\author{
Naiane Vieira dos Reis ${ }^{2}$ \\ Luiza Helena Oliveira da Silva ${ }^{3}$ \\ Universidade Federal do Tocantins
}

\begin{abstract}
RESUMO
Este trabalho investiga o processo de formação de leitores dos acadêmicos em turmas de uma licenciatura em Letras, analisando a competência modal desses sujeitos. Para análise, foram considerados diários de campo produzidos em um estágio em docência na disciplina de letramento literário e dados de uma pesquisa sobre prática de leitura no ensino superior, sendo focalizada a relação dos acadêmicos com a literatura. Embora fossem privilegiadas no curso as discussões teóricas sobre políticas de ensino, observou-se que não foi contemplado o contato com o texto literário no percurso de formação daqueles estudantes. São mobilizadas as contribuições da teoria literária, mais precisamente, as discussões sobre a recepção da leitura pelos sujeitos em diversos contextos sociais, e da semiótica discursiva, mobilizando a sintaxe do nível narrativo para analisar a relação do leitor com o objeto literário e as categorias de interação postuladas pela sociossemiótica. Considerando as competências do sujeito, o leitor quer, mas não sabe, pode ou deve entrar em contato com a literatura. Ainda que o texto literário seja considerado pelos licenciandos como um objeto-valor, o efetivo contato com a literatura acontece em circunstâncias pouco favoráveis à formação do gosto pelo estético, tendo em vista o pragmatismo das demandas da escolarização da leitura, além da idealização do ato de ler, concebido como distanciado da vida real e das necessidades cotidianas. A leitura de literatura vai sendo circunscrita, portanto, como uma habilidade cada vez mais atrelada aos grupos de maior privilégio social. O saber ler não constitui um gostar, sentir prazer na leitura ou apreciar as qualidades estéticas de um texto. Além das discussões teóricas acerca do ensino de literatura, é emergente a necessidade de privilegiar o letramento literário dos professores em formação inicial, tendo em vista que esses sujeitos, futuros mediadores de leitura, em alguns casos, ainda não são leitores.
\end{abstract}

PALAVRAS-CHAVE: ensino de leitura; semiótica discursiva; formação de professores; gosto.

\begin{abstract}
This work investigates the process of readers' formation of the students in classes of a degree in Language and Literature undergraduation class, analyzing the modal competence of these subjects. For the analysis, field diaries produced in a teaching internship in the subject of literary literacy and data of a research on reading practice in higher education were considered, with a focus on the relation between the students and the literature. Although the theoretical discussions

\footnotetext{
1 Este trabalho foi parcialmente apresentado em comunicação oral no V Congresso Internacional da ABES (Associação Brasileira de Estudos Semióticos), em abril de 2017, na Universidade Federal Fluminense, em NiteróiRJ.

2 Mestra em Letras; Doutoranda em Letras pelo Programa de Pós-graduação em Letras: Ensino de Língua e Literatura (PPGL) da Universidade Federal do Tocantins, Campus de Araguaína. E-mail: naianevieira@uft.edu.br

3 Professora do Programa de Pós-gradução em Letras (PPGL) e do Mestrado Profissional em Letras em Rede Nacional (ProfLetras) da Universidade Federal do Tocantins, Campus de Araguaína. E-mail: luiza.to@uft.ed.br
} 
on educational policies were privileged in the course, it was observed that the contact with the literary text in the training course of those students was not observed. The contributions of the literary theory are mobilized, more precisely, the discussions about the reception of reading by the subjects in different social contexts, and of the discursive semiotics, mobilizing the syntax of the narrative level to analyze the relation of the reader with the literary object and the categories of interaction strategies postulated by the sociosemiotics. Considering the competences of the subject, the reader wants, but does not know, can or should get in touch with literature. Although the undergraduate students consider the literary text as a value-object, the effective contact with literature occurs in circumstances that are not favorable to the formation of the aesthetic taste, in view of the pragmatism of the demands of reading schooling, besides of the idealization of the act of reading, conceived as distanced from the real life and everyday needs. The reading of literature is, therefore, circumscribed as an ability increasingly linked to groups of greater social privilege. Knowing how to read does not constitute a liking, pleasure in reading or appreciating the aesthetic qualities of a text. In addition to the theoretical discussions about literature teaching, the need to privilege the literary literacy of teachers in initial formation is urgent, considering that these subjects, future mediators of reading, in some cases, are not yet readers.

KEYWORDS: reading teaching; discursive semiotics; teacher formation; taste.

\title{
INTRODUÇÃO
}

\author{
A sensibilidade não é um dom inato, mas uma \\ qualidade que se desenvolve. \\ José Luiz Fiorin (2004, p. 108)
}

Em um curso de formação de professores de língua materna, é comum ouvir dos discentes que a opção pela licenciatura em Letras deu-se em função do gosto pelo texto literário. As narrativas quase sempre apontam a figura de um/a professor/a para que tal gosto fosse instaurado. Assim, anteriormente ao encanto pela literatura, há o contágio pelo gosto do outro. Gosta-se de textos literários porque o professor lia de forma a deslumbrar seus discentes, revelando no texto mundos que quem o ouvia não conseguiria perceber sem a mediação docente.

Se a literatura habita o imaginário dos estudantes ao optarem pelo curso que a toma como objeto de estudo, compreende-se, desse modo, que compõe o repertório cultural dos acadêmicos, o que nem sempre ocorre. Movidos pelo desejo de descobrir o texto, construir-lhe sentidos, o universo literário muitas vezes se revela como ambiente a ser explorado pelos estudantes de graduação. Considerando as relações observadas entre licenciandos e literatura, discutimos, neste trabalho, a formação leitora dos acadêmicos de Letras de uma universidade federal no norte do país, tendo em vista as relações que medeiam o contato dos sujeitos com o texto literário. Para tanto, lançamos mãos de observações registradas em diário de campo a partir de um estágio em docência na disciplina de "Letramento literário", além de considerarmos os dados de um trabalho de conclusão de curso sobre os desafios da formação leitora para os estudantes trabalhadores do curso de Letras da referida universidade (ALVES, 2016).

O perfil socioeconômico dos estudantes dos cursos de licenciatura da instituição focalizada revela que esses acadêmicos estão concentrados nas camadas sociais menos favorecidas economicamente (BRASIL, 2014). Diante de tal cenário, é notável o empenho dos estudantes em jornadas duplas ou triplas, uma vez que se desdobram entre trabalhar, estudar e cuidar do lar. Esse contexto de formação impacta no modo como a leitura é vivenciada pelos sujeitos, pois as demandas pragmáticas do cotidiano muitas vezes sobrepõem-se ao lazer e ao prazer estético. 
Ao tratar do estético, do literário, a sensibilidade ocupa lugar protagonista nas discussões sobre ensino de leitura. Seja pelos aspectos formais do texto, seja focalizando a subjetividade, as leituras de literatura são frequentemente orientadas por aquilo que causa estranhamento no sujeito, a partir de uma relação sensível com o objeto. Considerando justamente as interações dos sujeitos com outros sujeitos e com os objetos, lançamos mão das contribuições da semiótica discursiva para compreendermos a relação de sentido dos leitores com a literatura.

A teoria semiótica propõe, para modelo de análise do plano do conteúdo, um percurso gerativo de sentido que intenta compreender os elementos mais abstratos até os mais concretos do texto. Como define o Dicionário de Semiótica, o termo percurso constitui a ideia de construção de sentido em processo, que se dá "progressivamente, na medida em que implica não somente uma disposição linear e ordenada dos elementos entre os quais se efetua, mas também uma progressão de um ponto a outro, graças a instâncias intermediárias" (GREIMAS; COURTÉS, 2011, p. 362). Dentre os três níveis de análise - fundamental, narrativo e discursivo -, selecionamos o narrativo para analisar os processos de transformação dos sujeitos, tendo em vista os contextos formais de ensino de leitura. Para tanto, são analisadas as modalizações dos sujeitos leitores pelo poder, dever, querer e saber nas práticas situadas em ambiente formal de ensino, além das contribuições da sociossemiótica ao tratar das interações dos sujeitos e objetos.

\section{A relação com o estético no ensino de leitura}

São recorrentes os relatos sobre a influência que a figura de um leitor exerce sobre esses sujeitos em processo de desvelamento do texto literário. Movidos pela inquietação, os curiosos intentam descobrir o que causa encantamento naqueles que se dedicam horas a ler literatura. Observa-se a também emergência de um leitor em contextos que se apresentam como pouco favoráveis à formação do gosto pelo literário, tendo em vista o estrito pragmatismo relativo a algumas leituras demandadas. Nesse sentido, ao cumprir a meta de empréstimo de textos estabelecida pela instituição de ensino, ao fazer uma atividade ritualizada e tradicional de interpretação nas aulas de Língua Portuguesa em que se deve encontrar apenas uma resposta correta sempre alinhada à compreensão dos professores ou dos autores dos livros didáticos (REIS; SILVA, 2011), o sujeito pode encantar-se, apreciar o literário, mesmo sem uma mediação que conduza o leitor a observar o extraordinário na literatura. $O$ caráter obrigatório, compreendido disforicamente no trato com os textos literários, vai também dando lugar ao prazer, aí correspondendo ao olhar eufórico, positivo, sobre a leitura de literatura. O gosto, nessas circunstâncias, dá-se pelo acaso, acidente (LANDOWSKI, 2014; SILVA; MELO, 2015), a despeito de uma (falta de) formação leitora e mediação da leitura literária nos âmbitos formais de ensino.

Diante da estrita regularidade nas aulas de Língua Portuguesa, por exemplo, em que professores e estudantes estão programados ao percurso de uma aula tradicional, com atividades de leitura que pouco convidam os sujeitos a atribuírem sentidos ao texto, pode haver o encantamento pela linguagem, pelo enredo, por um personagem. Nesse sentido, o leitor deve, considerando as demandas a que está submetido nos ambientes de ensino, mas também quer ler, pois o texto encanta, envolve e seduz esse sujeito. Não são raros os relatos de estudantes que revelam seu gosto pelo estético formado a partir de pretensos castigos impostos pelas unidades de ensino, que como punição os obrigavam visitar a biblioteca e cumprir com um determinado número de leitura de textos literários. Se Umberto Eco (1994) nos faz uma caracterização distópica de uma biblioteca que em sua totalidade desencoraja e desestimula os seus visitantes e frequentadores, impondo-lhes vários desafios para o efetivo contato com o texto, a história de vida de muitos leitores vai revelando que esse lugar idealizado pelo semiólogo muito se aproxima 
de nossas experiências comuns, pois a prática de ler também é atravessada por entraves que tanto implicam e impactam no (não) gosto pelo literário.

O leitor em formação, na sua relação com o mundo, é movido pelo querer, pelo desejo de busca, seja do outro, do leitor, seja do significado pretensamente revelado do texto. Procura-se no texto a figura daquele que se pretende ser, o leitor idealizado, ou são encontrados na leitura sentidos para a própria vida. $\mathrm{O}$ encontro à subjetividade do sujeito é o que motiva a leitura literária e a busca pelo estético, sendo a literatura a instância de formação do leitor enquanto ser ancorado no seio social. Cândido (1995), ao falar sobre "O direito à literatura", pontua justamente sobre o papel e o impacto do literário na formação dos sujeitos enquanto seres complexos e dotados de subjetividade. Não se trata da formação do "bom sujeito" ou, tão reforçado pelo imaginário mais conservador e à direita brasileiro, do "homem de bem", mas, a despeito de um comportamento aprovável pela moralidade vigente, de um ser social movido pela incompletude, em constante formação, volúvel. Petit (2013) e Rouxel (2013), ao tratarem especificamente da subjetividade do leitor de literatura, também defendem que a leitura literária seja fundante na formação identitária dos sujeitos. Pela narrativa do outro, com o literário, o leitor vai construindo e dando sentido para a sua própria história e vivência.

"Ler Manoel de Barros me fez revisitar e reinventar toda a minha infância", "Madame Bovary sou eu", "Mário de Andrade e outros modernistas me fizeram enxergar de forma mais ampla o que podemos chamar de Brasil", "Paulo Coelho consegue dizer exatamente o que estou sentindo" são exemplos de falas sobre a experiência com a leitura de literatura. Seja pelo best seller muitas vezes desprezado pela crítica literária, ou o romance bastante apegado às estéticas romântica e realista e de estrutura pouco variável das bancas de jornal, seja pelo cânone e/ou bem recebido texto nos ambientes mais ligados à tradição acadêmica, é na relação subjetiva do leitor com o texto que é despertado o gosto, o prazer da leitura.

A subjetividade da leitura literária é compreendida como uma comunhão do leitor com o texto, isto é, tanto o sujeito atribui sentidos para o lido quanto o literário proporciona novas compreensões para a própria vida, numa relação de reciprocidade. Não apenas os leitores configuram-se como sujeitos que produzem sentidos para o objeto literário, mas o texto é composto por qualidades sensíveis que afetam o sujeito, resultando que "nem as coisas são meramente objetos sensíveis, sem alma, nem as pessoas puras sujeitos inteligíveis, sem corpo. Ao contrário, ambos falam a mesma linguagem complexa, em que a apreensão do sentido não é separável da escuta do sensível" (LANDOWSKI, 1997, p. 121).

Compreendemos essa interação sujeito - texto literário sob o regime do ajustamento, regido pelo princípio da sensibilidade, já que o leitor e a literatura se constroem mutuamente, isto é, têm "a capacidade de se sentir reciprocamente" (LANDOSWKI, 2014, p. 50 [grifo do autor]). O sociossemioticista Landowski (2014), ao propor e sistematizar os regimes de interação nos processos de transformação do sujeito previstos pela sintaxe do nível narrativo, considera justamente as relações sensíveis que, distintamente da competência modal, são dotadas de competência estésica. As noções de acidente (aleatoriedade, em que o sujeito se depara com o novo e inusitado) e o ajustamento são somadas às interações compreendidas como programação (regularidade, com interações tão ritualizadas e repetitivas que perdem o sentido) e a manipulação (intencionalidade, em que um sujeito faz outro querer fazer algo) já incorporadas ao modelo de análise pela teoria standard, observando justamente as interações no âmbito do sensível e estético. Ao discutirem as plurais relações que estabelecemos com a literatura, Silva e Melo (2015) apontam que, diferentemente do sujeito pragmático que instrumentaliza os objetos literários para fins outros que não a produção de sentidos para o lido, o sujeito sensível experimenta na leitura literária o gozo estético, resultante da comunhão entre leitor e texto.

Nos contextos de formação, na educação básica e/ou superior, parece haver pouco espaço para a formação propriamente dita do sujeito leitor. Conforme evidenciam as orientações 
e parâmetros curriculares para o ensino fundamental e médio, na educação básica há enfoque na variedade de gêneros a qual os sujeitos estão (ou poderão ser) expostos na sua vida cotidiana e, também, nos aspectos formais dos textos. Nesse sentido, o trabalho com o texto vai do conhecimento da diversidade de gêneros do discurso ao reconhecimento de sua forma e funções, quase sempre observando uma sintaxe geral, seja apontando a estrutura, o estilo, o tema etc., que atravessam e são comuns a uma variedade de escritos.

No trato com a literatura, analisar semanticamente o texto, isto é, observar as especificidades e singularidades de uma produção literária, o estilo único, o trabalho com a linguagem, vai ganhando cada vez menos enfoque em práticas de ensino que tomam o estético como objeto de investigação. A instrumentalização do leitor, considerando as políticas de leitura vigentes desde o século passado, objetiva a formação de um sujeito competente para observar a constituição de uma gama de gêneros textuais, sendo capaz de lê-los e produzi-los, a depender das demandas sociais. Certamente, o desenvolvimento de práticas de letramento diversas é necessário para a formação de sujeitos autônomos na sociedade. Entretanto, o estrito saber ler não implica necessariamente um gostar de ler, o que acarreta uma série de desafios ao ensino de leitura literária e formação do gosto pela literatura (MAGALHÃES; BARBOSA, 2009).

É justamente na articulação entre os elementos sintáticos e semânticos que entendemos ser formado o leitor, já que, à medida em que há encantamento pelo singular, além do reconhecimento e articulação do que é recorrente entre os escritos de literatura, o sujeito vai tornando-se autônomo para eleger seus próprios critérios de seleção e leitura do texto literário. Há, porém, um enrijecimento do ensino de leitura que muito se assemelha à abordagem da gramática tradicional na educação básica, quando a classificação em metalinguagem dos enunciados sobrepõe-se à compreensão do texto.

O ensino focalizando os vários gêneros discursivos tem frequentemente privilegiado o enquadramento dos diferentes textos num modelo rígido e pouco variável, em muitos casos simplificador e redutor na observação do funcionamento da língua. Com Luís Fernando Veríssimo estuda-se o gênero crônica, com Machado de Assis as orações subordinadas, com Marina Colasanti aprende-se a superar os obstáculos impostos pela vida. O texto continua sendo pretexto para ensinar outros aspectos (estrutura do gênero, lição de moral, classificação gramatical) que não necessariamente estão relacionados aos sentidos do lido (REIS; SILVA, 2012).

No âmbito da universidade, alguns licenciandos, ainda pouco familiarizados com a leitura, deparam-se com um grande volume de textos componente de sua formação e desdobramse para alcançar as demandas de leitura e escrita próprias do ambiente acadêmico. Mesmo que na licenciatura em Letras haja ampla abordagem do texto literário, a formação profissional pouco considera a possibilidade dos discentes ainda não serem leitores. Nesse sentido, ou os sujeitos desenvolvem habilidades de leitura por meios próprios ou serão excluídos do processo de aprendizagem, pois a academia espera de seu público uma formação básica que lhe subsidie uma performance leitora que atenda às suas demandas de letramento.

Com o intuito de formar profissionais que tomem o texto literário como objeto de ensino, na formação profissional a leitura de literatura é bastante formalizada, atendendo a demandas acadêmicas, respondendo a orientações teóricas. Lê-se para melhor entender a teoria literária, para compreender aspectos históricos de um povo ou lugar, para formular metodologias de ensino.

$\mathrm{Na}$ licenciatura em Letras, compreende-se que são orientados, capacitados e instrumentalizados formadores de leitores, profissionais capazes de performar uma leitura, de orientar a busca pelos sentidos do texto a partir da observação dos planos da expressão e do conteúdo, de despertar nos estudantes a habilidade de leitura e o gosto pelo texto literário. Entretanto, o graduando em alguns casos não é ou não se considera leitor, embora tenha acesso 
às teorizações sobre políticas de leitura, pedagogias de formação de leitores e metodologias de ensino de leitura de texto literário, pois não associa seu ato de ler a uma prática prazerosa.

A relação entre os sujeitos em formação profissional inicial e a literatura é marcada por alguns desafios: falta-lhes o acesso ao próprio texto literário, a habilidade para compreensão da literatura, o tempo livre para apreciação do estético etc. Modalizados por um não poder ser, ainda que tenham acesso a uma formação técnica sobre o ensino de leitura e literatura, os graduandos também caracterizam-se por um não saber ser leitor, uma vez que o texto literário se lhes apresenta como um objeto de difícil desvelamento, principalmente no tocante ao aspecto estético, àquilo que pode causar estranhamento no sujeito.

Por não ter experimentado uma formação literária que lhe proporcione a experimentação e apreciação do singular, o desvelamento e encantamento pelos surpreendentes arranjos da linguagem, o sujeito não se torna capaz de eleger para si os próprios critérios de leitura, sendo o contato com o texto sempre mediado pelo outro, atendendo inicialmente às demandas do outro. Pela tentação ("Se vocês lerem as quatro obras indicadas, poderão escolher o tipo de avaliação que mais gostam"), intimidação ("Quem não ler o romance até a próxima aula ficará reprovado em Literatura Brasileira III"), sedução ("É impressionante a sua capacidade de interpretação dos romances modernos. Você está perfeitamente apto a explorar outras estéticas") ou provocação ("Gostaria de trabalhar alguns contos de terror, mas duvido que vocês terão coragem de ler algum texto até o fim”), o professor (destinador) manipula o estudante (destinatário) a entrar em conjunção com a leitura literária.

Dotado da competência de leitura (saber ler), o sujeito observa a estrutura do gênero, o estilo, reconhece a produção literária de um tempo ou autor, sendo sancionado positivamente ao participar ativamente de uma roda de leitura, conquistar a vaga num concurso ou vestibular, ser aprovado na avaliação, galgar uma vaga de emprego ou ganhar uma promoção no trabalho. Nesse sentido, o objeto valor negociado pelos sujeitos, para além da apreciação estética do literário, é a ascensão social ou econômica diante de demandas pragmáticas do cotidiano.

Embora a formação de leitores seja uma preocupação na educação básica e superior, especialmente nas licenciaturas em Letras, as abordagens do texto literário nesses espaços partem do pressuposto de que o estudante é um sujeito leitor já experiente, mas que pode ser qualificado a observar formalmente aspectos do escrito que evidenciam ou comprovam a sua qualidade estética. Nesse sentido, a orientação de leitura é usualmente feita a partir da consideração dos aspectos formais do texto, observando as metáforas, os aspectos linguísticos que corroboram a leitura, as relações intertextuais estabelecidas através do lido.

O sujeito leitor tem como meta inicial de sua leitura a construção de significação para o texto, antes mesmo de experimentar o sensível. Nesse sentido, os espaços formais de ensino já demandam que seus alunos explicitem suas isotopias de leitura, justificando sua compreensão dos textos antes mesmo de qualquer socialização, de apontamentos daquilo que causa estranhamento ou da construção do sentido sensível para o lido.

Há um tipo de leitura ideal a ser construído, considerado objetivo, que elenca como critério para a construção competente de sentidos os aspectos que estariam além dos investimentos subjetivos do leitor. Se a apreciação estética acontece na junção do sujeito com o objeto, em momento de ruptura com a ordem do regular e cotidiano (GREIMAS, 2002), e a escolarização da leitura exige do leitor a constante inserção na ordem da regularidade, o contato sensível ocorre senão por acidente, mero acaso, na contramão do percurso idealizado.

\section{$2 \mathrm{O}$ gosto do gosto de ler}

Ao analisar o gosto erudito, médio e popular, considerando os apontamentos de Bourdieu (2015) sobre os elementos de distinção criados e recriados socialmente, marcados por classes sociais, Fiorin (1997, p. 21) observa que nesse imaginário dominante sobre a leitura "a 
gratuidade é o princípio que rege o gosto", tendo em vista a relação com os objetos que os sujeitos do bom gosto estabelecem. Tais sujeitos caracterizam-se como pertencentes às elevadas classes socioeconômicas e atuam como fundadores do que deve ser considerado bom e belo. Elencando como critérios de avaliação elementos abstratos e de aparente distanciamento do mundo natural, o sujeito do bom gosto objetiva criar efeito de sentido de objetividade, já que o belo seria distanciado e alheio a si.

Nessa direção, a interação ideal com o literário transcenderia o leitor e suas subjetividades, estabelecendo-se estritamente na observação de elementos textuais. A leitura da "justa medida", conforme observa o semioticista ao tecer sua crítica sobre os processos de dominação do gosto, seria aquela que aponta no próprio objeto semiótico elementos para sua significação (FIORIN, 1997). Compreender e gostar de "Felicidade clandestina" porque o sujeito leitor, assim como a protagonista do conto de Clarice Lispector, estabelece uma relação sensível com o objeto livro denunciaria, assim, critérios pouco objetivos de leitura. A partir dos apontamentos de Appiah (2014) sobre os termos objetividade e universalismo, consideradas as subjetividades locais eurocêntricas dominantes sobre outras culturas e modos de produção de sentido, compreendemos, então, que toda leitura é fundamentalmente subjetiva, mesmo que elenque como instrumento de interpretação critérios formais e aparentemente exteriores ao leitor.

Ao analisar memorial produzido por professores matriculados em um programa nacional de formação docente (PARFor), na disciplina de Letramento Literário, observamos que o primeiro contato com a literatura aconteceu, para muitos, durante o ensino superior, tendo em vista as demandas das disciplinas cursadas (SILVA; REIS, 2014). Discorrendo sobre a experiência de leitura, os docentes apontavam dois livros lidos sob orientação de uma professora formadora em uma determinada disciplina. A leitura fora feita para cumprimento de uma atividade pedagógica. Em outros casos, nos relatos em que se verificou uma experiência prévia de leitura, o gosto pelo literário foi descrito como um desvio, um acidente no percurso de vida previsto para aqueles sujeitos geralmente oriundo de classes populares e de zonas rurais. Observamos que nesses casos são recorrentes os eventos apontados por Petit (2010) ao tratar dos espectros que envolvem a prática de leitura, pois esta é não raramente compreendida como perigosa e nociva na formação das boas moças, na atuação do trabalhador rural, na interação dentro da comunidade, além de despertar a desconfiança sobre quem lê, um sujeito aparentemente ameaçador porque pouco se sabe sobre seus pensamentos.

O comportamento de leitura dos discentes da licenciatura em Letras parece pouco se modificar ao longo dos anos, sendo observado que há a prevalência dos que se declaram nãoleitores nos cursos de formação docente. Em estágio docente na disciplina de Letramento Literário, ao serem questionados sobre os hábitos de leitura literária, os acadêmicos declararam não ter familiaridade com a literatura, embora alguns rememorem, em momento anterior às demandas pragmáticas da vida adulta e do curso superior, um intenso contato com a literatura. $\mathrm{O}$ gosto pelo literário, nesse caso, remete quase sempre a uma experiência ligada à infância e à vivência familiar. Ao debater as práticas de leitura no cenário nacional, dando ênfase aos processos de mediação de leitura, Ceccantini (2009) aborda justamente o distanciamento dos sujeitos das práticas do ler com o passar das idades. Segundo o autor, se na infância a formação leitora acontece justamente pelo encantamento com o estético, a partir da adolescência o caráter "coercitivo" e controlado das leituras pouco permite que o sujeito aprecie o literário e engaje-se no trato com o texto (CECCANTINI, 2009, p. 220).

Ao manifestar o ato corriqueiro de ler, um licenciando declarara que faz leituras que lhes sirva para a vida, para entender melhor sua própria religião e religiosidade, para passar em concursos, para entender as discussões teóricas do curso de Letras. A leitura para esses estudantes que também são trabalhadores está inserida na ordem dos percursos pragmáticos a serem cumpridos pelos sujeitos, constituindo-se como uma dentre tantas outras atividades a 
serem desempenhadas de acordo com demandas prévias. A prevenção do risco diante do lido é estabelecida pelos objetivos utilitários da leitura, mesmo que o objeto de uso seja o texto literário, uma vez que o sujeito se propõe a "ver unicamente o que é para ser visto" (LANDOWSKI, 2004, p. 107-108).

Ao discorrer sobre o espaço social da leitura, discutindo sobre os fatores sociais, econômicos, de gênero que perpassam essa atividade, Petit (2013) observa que o ato de ler é sancionado negativamente pelas comunidades menos favorecidas economicamente, já que o ócio e o recolhimento individual são vistos como um descomprometimento com a coletividade. Compreendo a leitura literária como espaço para a construção das individualidades, que organiza o caos e dá sentido para as experiências vividas, Petit (2010) aponta que a privação do sujeito leitor do espaço e ordem de atividades coletivas é vista como uma ameaça ao regular, ao cotidiano, sendo muitas vezes pouco tolerada por alguns grupos sociais.

Com vistas à formação de formadores de leitores, privilegiamos na disciplina de Letramento Literário discussões acerca das políticas de leitura, mediação e formação de leitores. Fomos percebendo, pelos apontamentos e questões levantados pelos discentes, que a teorização sobre a leitura, principalmente a realizada em espaço escolar, era distanciada das experiências daqueles sujeitos. Uma questão emergia ao longo das aulas: como pensar a formação de leitores nas atividades futuras dos licenciandos, sendo que estes tinham pouca familiaridade com a leitura literária?

Nas experiências de leitura, é comum ouvir dos discentes que o livro recorrentemente lido é a Bíblia, já que muitos identificam-se como cristãos praticantes. Leem porque precisam conhecer os ensinamentos religiosos, porque é isso que os cristãos fazem, porque devem orientar suas vidas a partir dos preceitos bíblicos. Ainda que a leitura literária tenha um viés utilitário (lemos para analisar, para entender, para pensar, refletir, relaxar, esquecer, lembrar), o préestabelecimento do sentido a ser observado no texto previne o sujeito da surpresa e, também, da apreciação, da admiração diante do novo e inusitado. Ao analisar o corpo que sente, o sentido sensível, Landowski (2004, p. 108 [grifos do autor]) lembra que a estrita mediação da relação entre sujeitos e objetos é estabelecida por "um dever-ser-visto-conhecido-memorizado cuja admiração será chancelada". O regime de interação entre sujeitos e objetos é da ordem da manipulação, em que o destinatário sempre age e é sancionado pelo destinador que, no caso da escolarização, pode ser compreendido como o professor, o livro didático, a crítica literária. A performance do estudante estaria, nesse sentido, dotada da competência do reconhecimento das escolas literárias, dos gêneros textuais, do estilo do autor etc., levando-o a um percurso previamente definido e sem aberturas para imprevistos.

Focalizando a relação sensível entre sujeito e objeto estético, Greimas (2002, p. 34) trata a apreensão estética como "um querer recíproco de conjunção, como um encontro, no meio do caminho, entre o sujeito e o objeto". A leitura, desse modo, não se trata meramente do debruçar do sujeito leitor sobre o texto literário para dele apreender significados previamente definidos, mas da relação sensível com a literatura, apreciando-a ou gozando de sua estética. Se nas vivências e saberes do leitor constroem-se os sentidos, é pelas marcas e aberturas do texto que o sujeito vai elaborando significados para o lido e para a própria vida (ISER, 1996). Tanto o texto quanto o leitor cooperam para a emergência do sentido e do próprio prazer estético na leitura literária.

Cética quanto ao prazer despertado pela leitura de um cânone da literatura brasileira, uma estudante demonstrou interesse em ler Antologia poética de Manuel Bandeira, embora não demonstrasse interesse pelo autor da obra. O desejo pelo texto fora provocado a partir de uma mediação de leitura em sala de aula na disciplina mencionada, quando observamos aspectos relativos à sonoridade e ao ritmo do poema Os sinos. Após um primeiro momento de leitura em vOz alta, foi manifestada pouca compreensão do texto. Assim, passamos a discutir os sentidos 
possíveis para cada estrofe do poema, além de observar a sonoridade evidente a partir da construção do texto. A partir do apontamento de elementos mais abstratos e sintéticos sobre o texto ("o poema fala sobre saudade", "aborda a questão do tempo, da passagem do tempo", "vida e morte é o tema do poema"), observamos juntamente com os licenciandos as isotopias de leitura para cada sentido diferente atribuído ao lido. Após esse momento, uma licencianda demonstrou, a partir de sua reação à leitura ("Se é assim que se lê, então eu também sei ler"), a mudança de um estado de impotência - não saber e não poder ler - para a competência - saber e poder ler. É na mudança de estado modal dos sujeitos que se observa o comportamento de leitura perene, no nosso caso, de estudantes de licenciatura, pois passam a lidar com o texto como um objeto compreensível, acessível.

Numa pesquisa de sobre a prática de leitura dos estudantes trabalhadores (ALVES, 2016), os professores em formação inicial revelam que, embora a obrigatoriedade perpassasse o contato com a literatura, o gosto se desenvolve tanto pelo mero contato com o literário quanto pela mediação docente:

Joana: $\mathrm{Na}$ faculdade desenvolveu mais esse meu gosto pela leitura assim, porque aqui a gente é obrigado a ler, eu vejo como uma leitura obrigatória, pela falta de tempo, por ter filho família, e ter que trabalhar pra ajudar em casa, por você ler as coisas correndo e às vezes você não entende daí você tem que arranjar um tempinho pra você estar lendo porque não é aquela prática habitual de gosto pela leitura. Não, é obrigatoriedade, pelo menos no meu caso. Poucas leituras que você faz e que você gosta pelo menos eu gostei mais das aulas de Literatura Portuguesa, porque eu fui obrigada a ler e eu terminei gostando. E também aprendi muito também a ler e estou aprendendo a gostar de ler agora com o professor Fulano [não identificado por questões éticas], que eu costumo dizer pra ele que eu estou aprendendo a ler com ele. (ALVES, 2016, p. 34)

Hélio: Como é é é no trabalho, quem trabalha e estuda é um pouco difícil, [a leitura] ficou um pouco mais na obrigatoriedade mesmo. Por causa do trabalho e do estudo, né, não é fácil, não dá tempo, a gente anda sempre cansado e sem tempo. Daí, faz as leituras dá. Não dava pra conciliar os dois com tantas leituras. (ALVES, 2016, p. 35)

Embora modalizada pelo dever ler (a gente é obrigada a ler), a estudante também passa por um momento de aprendizagem da leitura mediada pelo docente, o que resulta em um gostar de ler (aprendendo a ler com ele). Se, pela agitação da vida diária, muitas vezes Joana não se dedica ao prazer da leitura, o saber ler pode possibilitar práticas de leitura que seriam também perpassadas pelo gostar de ler. Numa interação de manipulação, o destinador faculdade ou professora de literatura faz o destinatário, a acadêmica Joana, dedicar-se à leitura, ainda que essa prática seja marcada por sobressaltos, como o caso do cuidado com a família, casa e dedicação ao trabalho. Entretanto, o dever ler vai dando lugar ao querer ler, marcado pelo gosto, em que o sujeito vai sendo seduzido pelo texto, apreciando-o ("eu gostei mais das aulas de Literatura Portuguesa, porque eu fui obrigada a ler e eu terminei gostando"). Se o contato inicial acontece em função das demandas da disciplina, que estipula textos e obras a serem analisados num curto período de tempo, a relação mais afetada com o literário é experimentada também em função do apender a ler com o outro, o professor. Nesse sentido, vemos a mudança nas interações, indo do caráter mais pragmático ao mais sensível, pois, se inicialmente Joana é manipulada pelo dever ler, posteriormente é contagiada pelo saber de seu professor, pois ela lêe com, que se configura, segundo Landowski (2014, p. 50), "por meio de um fazer conjunto".

Por outro lado, também são enunciadas as impossibilidades de comunhão entre tempo da leitura e tempo do trabalho, conforme declara Hélio em seu depoimento. No segundo relato, podemos observar que o sujeito, caracterizado como estudante-trabalhador, não experimenta um querer ler e tem, muitas vezes, um poder ler atravessado por entraves que dizem mais sobre as condições em que são realizadas as leituras do que sobre sua competência de desvendar os 
sentidos de lido ("quem trabalha e estuda é um pouco difícil, [a leitura] ficou um pouco mais na obrigatoriedade mesmo").

Fica claro ao observar os dois relatos que o contexto de formação de professores de Letras é plural e conflituoso. Se o curso de graduação demanda de seus acadêmicos uma formação literária ampla, que viabilize ao mesmo tempo competência analítica e sensibilidade estética, nem sempre os dota de competência para realização e tal performance leitora. Os licenciandos devem ler em função da disciplina cursada, mas o seu gosto pela leitura pode ou não ser desenvolvido. A mediação das práticas de leitura para o despertar da sensibilidade do literário é imprescindível nos espaços de ensino, como evidencia o primeiro relato citado acima. Mesmo diante de condições pouco favoráveis à apreciação do estético, com falta de tempo, excesso de tarefas e pragmatismo da leitura, o gosto pode ser desenvolvido e impacta no próprio modo como os acadêmicos se relacionam com o curso, como vimos no nosso estágio, em que os autodenominados leitores envolviam-se e apropriavam-se de forma mais profícua dos textos, tanto literários quanto acadêmicos, pois tratavam-se de discussões que não eram estranhas às suas realidades.

Quando o prazer da leitura se dá por uma relação de ajustamento, em que o estudante gosta de ler pelo gosto ou mediação de leitura do docente, muitas vezes se dando em decorrência de um aprendizado desenvolvido, acreditamos que ocorre a efetiva formação de leitores. Mesmo no nível superior de formação, a sensibilidade precisa ser, como diz Fiorin (2004) na nossa epígrafe, desenvolvida. O gosto não pode ser considerado um dom, uma habilidade exclusiva de alguns poucos sujeitos, sendo que apenas os "iluminados" têm o privilégio de apreciação do estético.

\section{CONSIDERAÇÕES FINAIS}

O processo de formação de leitores apresenta-se como desafio para as várias etapas de ensino, seja na educação básica e/ou superior. Como docentes envolvidos em pesquisa sobre ensino de literatura e engajados em práticas de mediação de leitura com vistas ao desenvolvimento do gosto pelo estético, compreendemos que o trato com os aspectos formais e estruturais do texto precisa alinhar-se a uma experiência subjetiva sensível de contato com o texto. Ser leitor competente é também poder se permitir momentos de fruição, de deleite, não se dedicando exclusivamente a responder corretamente uma atividade ou a realizar uma tarefa a partir da leitura.

Se a formação de leitores ganhar cada vez menos espaço na educação básica e nos cursos de Letras, observamos que pode ocorrer uma espécie de círculo vicioso em que nenhuma etapa de ensino se dedica precisamente à sua sistematização. Nesse sentido, os sujeitos que saem da educação básica sem passar pela experiência prazerosa de leitura retornam à sala de aula como professores pouco sensíveis ao literário, já que sua formação acadêmica pode também não ter favorecido a experiência estética.

Pela aleatoriedade, mero acaso, um acidente diante da estrita regularidade a que são submetidos os sujeitos nos rituais de leitura em ambiente formal de ensino, em que o gosto pela leitura acontece apesar dos percursos de ensino vivenciados, a educação básica e superior pouco apresentam sistemáticas pedagogias de formação de leitores literários. Ainda que a compreensão dos aspectos formais seja uma instância de leitura que contribui para o despertar do gosto pela literatura, a ritualização e programação de aulas que focalizem estritamente tais aspectos podem resultar numa interação dessemantizada, despertando, pelo contrário do que é almejado, a aversão ao literário. Os ambientes formais de ensino, nesse sentido, têm papel importante na formação do gosto sensível, pois podem mediar a leitura de modo a conduzir os sujeitos na observação daquilo que o texto tem de único, belo e envolvente. Nesse sentido, compreendendo 
que não se trata de uma habilidade inata ou que é desenvolvida apenas por aqueles "sensíveis por natureza”, entendemos que o prazer pela leitura precisa ser ensinado.

\section{REFERÊNCIAS BIBLIOGRÁFICAS}

ALVES, Mayara de Almeida Matos. Quando os leitores são trabalhadores: conversas com professores em formação inicial. 2016. 55 f. Trabalho de Conclusão de Curso - Faculdade de Letras-Português, Universidade Federal do Tocantins, Araguaína, 2016.

APPIAH, Kwame Anthony. Na casa de meu pai: a África na filosofia da cultura. Rio de Janeiro: Contraponto, 1997.

BRASIL. IV pesquisa do perfil socioeconômico e cultural dos estudantes de graduação das instituições federais de ensino superior no Brasil. Uberlândia: FONAPRACE/ANDIFES, 2014, $391 \mathrm{p}$.

BOURDIEU, Pierre. A distinção: crítica social do julgamento. 2a ed. Porto Alegre: Zouk, 2015.

CÂNDIDO, Antonio. O direito à Literatura. In: Vários escritos. São Paulo: Duas Cidades, 1995.

CECCANTINI, João Luís. Leitores iniciantes e comportamento de leitura. In: SANTOS, F.; MARQUES NETO, J. C.; RÖSING, T. M. K. (Orgs). Mediação de leitura: discussões alternativas para a formação de leitores. São Paulo: Global, 2009, p. 207-231.

ECO, Umberto. A biblioteca. Lisboa: Difel, 1994.

FIORIN, José Luiz. Linguística e pedagogia de leitura. Scripta, Belo Horizonte, v. 7, n. 14, 2004.

De gustibus non est disputandum? In: LANDOWSKI, E.; FIORIN, J. L. (Org.). O gosto da gente, o gosto das coisas: abordagem semiótica. São Paulo: Educ, 1997, p. 13-28.

GREIMAS, A. J. Da imperfeição. São Paulo: Hacker, 2002.

.; COURTÉS, J. Dicionário de semiótica. $2^{\text {a }}$ ed. São Paulo: Contexto, 2011.

ISER, Wolfgag. O ato da leitura: uma teoria do efeito estético, Vol. 1. São Paulo: Editora 34, 1996.

LANDOWSKI, Eric. Interações arriscadas. São Paulo: Estação das Letras e Cores/Centro de Pesquisas Sociossemióticas, 2014.

Modos de presença do visível. In: OLIVEIRA, A. C. Semiótica plástica. São Paulo: Hacker Editores, 2004, p. 97-112.

Gosto se discute. In: LANDOWSKI, E; FIORIN, J. L. O gosto da gente, o gosto das coisas: abordagem semiótica. São Paulo: Educ, 1997.

MAGALHAES, H. G. D.; BARBOSA, E.P.S . Letramento literário na alfabetização. In: Wagner Rodrigues Silva e Lívia Chaves de Melo (Org.). Pesquisa \& ensino de língua materna e literatura: diálogos entre formador e professor. Campinas: Mercado das Letras, 2009.

PETIT, Michèle. Leituras: do espaço íntimo ao espaço público. São Paulo: Editora 34, 2013.

A arte de ler: ou como resistir à adversidade. 2. ed. São Paulo: Editora 34, 2010. 
REIS, Naiane Vieira dos; SILVA, Luiza Helena Oliveira da. Texto literário em prosa em material de formação continuada: uma análise semiótica. II CIELLI - Colóquio Internacional de Estudos Linguísticos e Literários, Maringá, 2012. p. 1-13.

Lendo poesia na escola: análise de orientações para a leitura do gênero poema em material de formação continuada. In: SILVA, N. L.; ALMEIDA, V. (Orgs.). Reflexões sobre ensino e formação de professores: Diálogos entre Educação Superior e Básica. Palmas: Nagô, 2011, p. 87-100.

ROUXEL, Annie. Autobiografia de leitor e identidade literária. In. ROUXEL, A.; LANGLADE, G; REZENDE, N. L. (Orgs.). Leitura subjetiva e ensino de literatura. São Paulo: Alameda editorial, 2013, p. 67-87.

SILVA, Luiza Helena Oliveira da; MELO, Márcio Araújo. O que pode o leitor? EntreLetras (Online), v. 6, p. 120-132, 2015.

.; REIS, Naiane Vieira dos. Diálogos virtuais e regimes de sentido: análise semiótica de chats em contexto de ensino. In: TEIXEIRA, Lucia; CARMO JR, José Roberto. (Orgs). Linguagens na cibercultura. São Paulo: Estação das Letras e Cores, 2013, v. 1, p. 237-271.

Submetido em 15/03/2018

Aceito em 19/08/2018 